\title{
Second-generation colon capsule endoscopy for detection of colorectal polyps: Systematic review and meta-analysis of clinical trials
}

\section{다)(i) $(5)$}

Authors

Tobias Möllers', Matthias Schwab 2,3,4,5, Lisa Gildein ${ }^{6}$, Michael Hoffmeister ${ }^{1}$, Jörg Albert ${ }^{6}$, Hermann Brenner ${ }^{1,7,8}$, Simon Jäger ${ }^{2,3}$

Institutions

1 Division of Clinical Epidemiology and Aging Research, German Cancer Research Centre, Heidelberg, Germany

2 Dr. Margarete Fischer Bosch Institute of Clinical Pharmacology, Clinical Pharmacogenomics and Cancer, Stuttgart, Germany

3 Department of Clinical Pharmacology, University Hospitals Tubingen, Tubingen, Germany

4 Department of Pharmacy and Biochemistry, University of Tübingen, Tübingen, Germany

5 German Cancer Consortium, Partner Site Tubingen, Tubingen, Germany

6 Department of Gastroenterology and Hepatology, Robert Bosch Hospital, Stuttgart, Germany

7 Division of Preventive Oncology, National Center for Tumor Diseases, Heidelberg, Germany

8 German Cancer Consortium, Heidelberg, Germany

submitted 7.7.2020

accepted after revision 19.10.2020

Bibliography

Endosc Int Open 2021; 09: E562-E571

DOI 10.1055/a-1353-4849

ISSN 2364-3722

(c) 2021. The Author(s).

This is an open access article published by Thieme under the terms of the Creative Commons Attribution-NonDerivative-NonCommercial License, permitting copying and reproduction so long as the original work is given appropriate credit. Contents may not be used for commercial purposes, or adapted, remixed, transformed or built upon. (https://creativecommons.org/licenses/by-nc-nd/4.0/)

Georg Thieme Verlag KG, Rüdigerstraße 14,

70469 Stuttgart, Germany

Corresponding author

Dr. Tobias Möllers, German Cancer Research Center (DKFZ), Division of Clinical Epidemiology and Aging Research, Im Neuenheimer Feld 581, 69120 Heidelberg, Germany Fax: +496221421302

t.moellers@dkfz-heidelberg.de
丹 Supplementary material is available under

https://doi.org/10.1055/a-1353-4849

\section{ABSTRACT}

Background and study aims Adherence to colorectal cancer (CRC) screening is still unsatisfactory in many countries, thereby limiting prevention of CRC. Colon capsule endoscopy (CCE), a minimally invasive procedure, could be an alternative to fecal immunochemical tests or optical colonoscopy for CRC screening, and might increase adherence in CRC screening. This systematic review and meta-analysis evaluates the diagnostic accuracy of CCE compared to optical colonoscopy (OC) as the gold standard, adequacy of bowel preparation regimes and the patient perspective on diagnostic measures.

Methods We conducted a systematic literature search in PubMed, EMBASE and the Cochrane Register for Clinical Trials. Pooled estimates for sensitivity, specificity and the diagnostic odds ratio with their respective $95 \%$ confidence intervals $(\mathrm{Cl})$ were calculated for studies providing sufficient data.

Results Of 840 initially identified studies, 13 were included in the systematic review and up to 9 in the meta-analysis. The pooled sensitivities and specificities for polyps $\geq 6 \mathrm{~mm}$ were $87 \%$ (95\% Cl: $83 \%-90 \%$ ) and $87 \%$ (95\% Cl: $76 \%-$ $93 \%$ ) in 8 studies, respectively. For polyps $\geq 10 \mathrm{~mm}$, the pooled estimates for sensitivities and specificities were $87 \%$ (95\% Cl: $83 \%-90 \%)$ and $95 \%(95 \% \mathrm{Cl}: 92 \%-97 \%)$ in 9 studies, respectively. A patients' perspective was assessed in $31 \%(n=4)$ of studies, and no preference of CCE over OC was reported. Bowel preparation was adequate in $61 \%$ to $92 \%$ of CCE exams.

Conclusions CCE provides high diagnostic accuracy in an adequately cleaned large bowel. Conclusive findings on patient perspectives require further studies to increase acceptance/adherence of CCE for CRC screening. 


\section{Introduction}

Colorectal cancer (CRC) is one of the most common cancers worldwide as well as one of the leading causes of death from cancer among women and men [1]. Contrary to other cancers, CRC usually develops slowly from non-advanced adenomas to advanced adenomas and CRC over many years [2]. This offers a great opportunity for prevention in form of screening measures such as optical colonoscopy (OC) or fecal immunochemical tests (FIT). Despite the variety of secondary prevention measures being available [3], the number of individuals accepting screening offers for CRC remains low. During the initial 10 years of the German screening colonoscopy program, only about $25 \%$ of eligible individuals (55-79 years old) actually underwent $O C$ for screening purposes [4]. Substantial efforts have been made to increase screening participation. This includes pre-announcement letters, personal invitation that includes the FIT, and reminder letters for FIT testing or personal invitations for $\mathrm{OC}$, all of which have led to a higher screening adherence [5-7]. Further increase in screening adherence could potentially reduce the incidence of and mortality from CRC [8]. Nevertheless, barriers such as a lack of awareness of the risks of CRC and negative attitudes towards the screening procedures decrease the participation in CRC screening programs [9].

Therefore, other ways to increase participation in CRC screening have to be considered, which include alternative procedures beyond OC or FIT. Colon capsule endoscopy (CCE) has been available since 2006 and is already recommended in case of incomplete OC or patient refusal to undergo the OC procedure $[10,11]$. In addition, CCE has shown considerable advances in its accuracy to detect polyps with the introduction of the second-generation capsules. This has been confirmed in a meta-analysis of CCE studies published in 2016, where polyps $\geq 10 \mathrm{~mm}$ were detected with a pooled sensitivity and specificity of $87.3 \%$ and $95.3 \%$, taking OC as the reference standard [12]. CCE might increase participation in CRC screening [13], and serve as a possible filter test to decide which individual should undergo OC [14]. However, CCE is not an established part of CRC screening programs to date.

To support the discussion of CCE as a CRC screening method, we conducted an updated systematic review and meta-analysis on the diagnostic accuracy of the second generation CCE (CCE2) compared to the gold standard OC. As a secondary aim, we assessed the patient perspective on diagnostic measures reported in the included clinical trials which will be an important aspect for the acceptance of CCE in the screening setting.

\section{Materials and methods}

\section{Data sources and search strategy}

The Preferred Reporting Items for Systematic Reviews and Meta-Analyses (PRISMA) guidelines were followed. A protocol was submitted to PROSPERO but no identification number has been assigned by the time of submission of the manuscript. PubMed, EMBASE and the Cochrane Central Register of Controlled Trials were searched from inception to January 22,
2020. Medical subject headings, non-medical subject headings terms and synonyms for the following terms were used to identify possible studies for inclusion: Colon AND Polyps AND Colon capsule endoscopy. The full list of search terms is given in $>$ Table 1. The reference lists of studies eligible for full-text screening were searched for additional relevant studies.

\section{Study selection}

Eligibility criteria included full-texts of clinical trials published in English or German language, the use of CCE-2, OC as the reference standard, a clear comparison of CCE-2 and OC, participants from an average risk screening population (i.e. persons at an average risk of developing (RC), patients with family history of CRC, patients referred after positive FIT/fecal occult blood test (FOBT) or imaging tests or a study population with a range of indications. Exclusion criteria included: CCE-2 studies with other endpoints than polyps, neoplasia, adenomas or CRC, a suboptimal reference standard (e.g. computed tomographic colonography [CTC]), and other study designs than clinical trials (database analysis). Based on our eligibility criteria, two reviewers (TM and SJ) performed the study selection independently. In case of discrepancy, discussion and further review followed.

\section{Data extraction}

Data extraction was done independently by two reviewers (TM and SJ or LG) and included the following information: author, year of publication, country(ies), number of centers, study design, bowel preparation protocol, availability of either or both per-patient and per-polyp analysis, timing of OC and CCE-2, unblinding of CCE-2 results at OC, number of patients enrolled/ included, reasons for exclusion, age (mean or median), sex distribution, indications for CCE-2/OC, patient perspective questions/questionnaire and result of patient perspective, rate of adequate cleansing at CCE-2, CCE-2 excretion rates at different timings ( $<8$ hours, $8-10$ hours, $>10$ hours), colon transit time, values of diagnostic accuracy, number of patients with any polyp size or $\geq 6 \mathrm{~mm} / \geq 10 \mathrm{~mm}$ polyps at CCE- 2 and OC, number of patients with at least 1 adenoma of any size or $\geq 6 \mathrm{~mm} / \geq 10 \mathrm{~mm}$ at CCE-2 and OC, number of patients with at least 1 invasive CRC at CCE-2 and OC, rate of adverse events at CCE-2 and OC.

\section{Risk of bias assessment}

The Quality assessment of Diagnostic Accuracy in Systematic Reviews - 2 (QUADAS-2) tool was used to assess methodological quality and potential bias among included studies by two independent reviewers (TM, LG) [15].

\section{Descriptive synthesis}

All included full texts were part of the descriptive synthesis for the following aspects: characteristics of included studies, patient perspectives, bowel preparation and rate of adequate cleansing, study related adverse events as well as diagnostic accuracy of polyps and adenomas. 
- Table 1 Characteristics of included studies.

\begin{tabular}{|c|c|c|c|c|c|c|c|c|c|c|}
\hline \multirow{2}{*}{$\begin{array}{l}\text { Author, } \\
\text { year }\end{array}$} & \multirow[t]{2}{*}{ Country(ies) } & \multirow{2}{*}{$\begin{array}{l}\text { Sample } \\
\text { size en- } \\
\text { rolled/ } \\
\text { included }\end{array}$} & \multirow{2}{*}{$\begin{array}{l}\text { Age in } \\
\text { years }\end{array}$} & \multirow{2}{*}{$\begin{array}{l}\text { Fe- } \\
\text { male } \\
\%\end{array}$} & \multicolumn{6}{|c|}{ Indications, n (\%) } \\
\hline & & & & & $\begin{array}{l}\text { CRC } \\
\text { Screen- } \\
\text { ing }\end{array}$ & FOBT/FIT + & FDR & $\begin{array}{l}\text { Perso- } \\
\text { nal/fam- } \\
\text { ily his- } \\
\text { tory }\end{array}$ & $\begin{array}{l}\text { Symp- } \\
\text { toms }\end{array}$ & $\begin{array}{l}\text { Oth- } \\
\text { er }\end{array}$ \\
\hline $\begin{array}{l}\text { Rex, } 2015 \\
\text { [19] }\end{array}$ & USA, Israel & $884 / 689$ & MN: 57 & 56 & $\begin{array}{l}689 \\
(100)\end{array}$ & - & - & - & - & - \\
\hline $\begin{array}{l}\text { Voska, } 2019 \\
\text { [22] }\end{array}$ & Czech Republic & $236 / 225$ & MN: 59 & 47 & $\begin{array}{l}225 \\
(100)\end{array}$ & - & - & - & - & - \\
\hline $\begin{array}{l}\text { Holleran, } \\
2014 \text { [14] }\end{array}$ & Ireland & $N A / 62$ & MN: 63 & 45 & - & $62(100)$ & - & - & - & - \\
\hline $\begin{array}{l}\text { Rondonotti, } \\
2014 \text { [24] }\end{array}$ & Italy & $54 / 50$ & MN: 59 & 42 & - & $50(100)$ & - & - & - & - \\
\hline $\begin{array}{l}\text { Kobaek- } \\
\text { Larsen, } \\
2017 \text { [21] }\end{array}$ & Denmark & $380 / 253$ & MD: 64 & 42 & - & $253(100)$ & - & - & - & - \\
\hline $\begin{array}{l}\text { Pecere, } \\
2019 \text { [23] }\end{array}$ & Italy, Spain & $222 / 178$ & MN: 61 & 44 & - & $178(100)$ & - & - & - & - \\
\hline $\begin{array}{l}\text { Adrian-de- } \\
\text { Ganzo, } 2015 \\
{[25]}\end{array}$ & Spain & $325 / 233$ & MD: 55 & 52 & - & - & $\begin{array}{l}233 \\
(100)\end{array}$ & - & - & - \\
\hline $\begin{array}{l}\text { Parodi, } 2018 \\
\text { [26] }\end{array}$ & Italy, Spain & $230 / 177$ & MD: 57 & 55 & - & - & $\begin{array}{l}177 \\
(100)\end{array}$ & - & - & - \\
\hline $\begin{array}{l}\text { Kroijer, } 2019 \\
{[27]}\end{array}$ & Denmark & $\mathrm{NA} / 180$ & MN: 59 & 48 & - & - & - & $\begin{array}{l}180 \\
(100)\end{array}$ & - & - \\
\hline $\begin{array}{l}\text { Eliakim, } \\
2009 \text { [20] }\end{array}$ & Israel & $103 / 98$ & MN: 50 & 34 & $31(32)$ & $21(21)$ & - & $33(34)$ & $20(20)$ & - \\
\hline $\begin{array}{l}\text { Spada, } 2011 \\
{[28]^{1}}\end{array}$ & $\begin{array}{l}\text { Italy, Spain, } \\
\text { Germany, Bel- } \\
\text { gium, Nether- } \\
\text { lands, France, } \\
\text { Sweden }\end{array}$ & $117 / 109$ & MN: 60 & 39 & $25(21)$ & $7(6)$ & - & $52(44)$ & $68(58)$ & - \\
\hline $\begin{array}{l}\text { Hagel, } 2014 \\
\text { [18] }\end{array}$ & Germany & $\mathrm{NA} / 24$ & MN: 51 & 42 & $13(55)$ & - & - & $7(29)$ & - & $\begin{array}{l}4 \\
(16)\end{array}$ \\
\hline $\begin{array}{l}\text { Morgan, } \\
2016[29]^{1}\end{array}$ & USA & $51 / 50$ & MN: 60 & 55 & $28(56)$ & $1(2)$ & - & $11(22)$ & $29(58)$ & - \\
\hline Total ${ }^{1}$ & & $\begin{array}{l}2,868 / \\
2,328\end{array}$ & - & - & $\begin{array}{l}1011 \\
(43.4)\end{array}$ & $572(24.6)$ & $\begin{array}{l}410 \\
(17.6)\end{array}$ & $\begin{array}{l}283 \\
(12.1)\end{array}$ & $\begin{array}{l}117 \\
(5.0)\end{array}$ & $\begin{array}{l}4 \\
(0.2)\end{array}$ \\
\hline
\end{tabular}

CRC, colorectal cancer; FDR, first-degree relative; FIT, fecal immunochemical test; FOBT, fecal occult blood test; MD, median; MN, mean; NA, not available.

${ }^{1}$ Some patients were enrolled for more than one indication.

\section{Statistical analysis}

Per-patient sensitivity, specificity and the diagnostic odds ratio (DOR) with the respective $95 \%$ confidence interval $(\mathrm{Cl})$ were calculated among individual studies providing sufficient data for polyps $\geq 6 \mathrm{~mm}$ and polyps $\geq 10 \mathrm{~mm}$. Heterogeneity was calculated by chi-squared based $\mathrm{Q}$ tests and the inconsistency in$\operatorname{dex} \mathrm{I}^{2}$. Random-effects models were calculated when significant heterogeneity ( $Q$ test of $p<.05$ or $\mathrm{I}^{2}>50 \%$ ) was present, otherwise fixed-effects models were used. Subgroup analyses were conducted based on the indication when possible. Deek's funnel plots were created and Begg's and Egger's tests were done to assess potential publication bias. The analyses were done using the "meta" and "mada" packages in $\mathrm{R}$ version $3.16 .3[16,17]$. All statistical tests were two-sided and $P<.05$ was considered statistically significant. 


\section{Results}

\section{Search results}

The search identified 840 articles, of which 213 duplicates were removed ( $\triangleright$ Fig. 1). After careful title and abstract screening, 38 articles remained for full text review. One additional publication was identified by screening of the reference list of those studies. Of the 39 articles selected for full-text review, 26 were excluded for the following reasons: 12 studies used the first generation of CCE, for seven articles no full-text was available (e.g. conference abstracts), three studies were not clinical trials (e. g. database analysis), two studies enrolled participants with an indication excluded by our review's study protocol, one study had no clear comparison of CCE-two and OC, and one study assessed a different endpoint. A total of 13 studies met the criteria to be included in the systematic review, of which nine were eligible for meta-analyses.

\section{Study characteristics}

Study characteristics of included studies are displayed in $>$ Table 1. Overall, 2,328 participants were included in the studies (24 [18] to 689 [19]). Mean or median age of participants ranged from 50 years [20] to 64 years [21] and 34\% [20] to $56 \%$ [19] of participants were female. Studies were conducted among an average risk screening population $(n=2)[19,22]$, FIT/FOBT + test individuals $(n=4)[14,21,23,24]$, first degree relatives (FDR) of CRC patients $(n=2)[25,26]$, patients with personal or family history $(n=1)$ [27], and mixed populations $(n=4)[18,20,28,29]$. In total, 1011 (43.4\%), 572 (24.6\%), 410 (17.6\%), 283 (12.1\%), 117 (5.0\%), 4 (0.2\%) participants were included because of average risk CRC screening, FIT/ FOBT + tests, FDR of CRC patients, personal/family history, gastrointestinal symptoms or other reasons, respectively.

\section{Risk of bias and publication bias}

The risk of bias for each study is shown in Table A2. A low, unclear or high risk of bias was present in 5, 6, and 1 study, respectively. The index test was rated with a low risk of bias for all studies. Only 1 study had a high risk of bias for the reference standard and two for the flow and timing of patients.

The funnel plots for publication bias can be seen in Fig. A1. There was no evidence for publication bias from the logarithms of DOR for studies with polyps $\geq 6 \mathrm{~mm}$ ( $n=8$; Egger's test: $P$ $=.4741$, Begg's test: $P=.6523$ ) or $\geq 10 \mathrm{~mm}$ ( $n=9$, Egger's test: $P=.7075$, Begg's test: $P=1.000)$.

\section{Patient perspectives}

The results of the patient perspective are shown in $>$ Table 2 . Overall, four studies (31\%) reported an assessment of the patient perspective. The participants in one study preferred OC $(n=120,53 \%)$ over CCE-2 ( $n=105,47 \%)$ [22], while $41 \%(n=$ 72 ) preferred CCE-2 over OC ( $n=40,23 \%$ preferred OC; $n=65$, $37 \%$ had no preference) in another study. [26] In a trial comparing CCE-2, CTC and OC, $78 \%(n=39)$ preferred CCE-2 over CTC $(n=11,22 \%)$, however "preference for OC" was not given as an option for that question. [24] In the study by Adrian-de-Ganzo et al., which allowed patients to switch groups after randomiza-

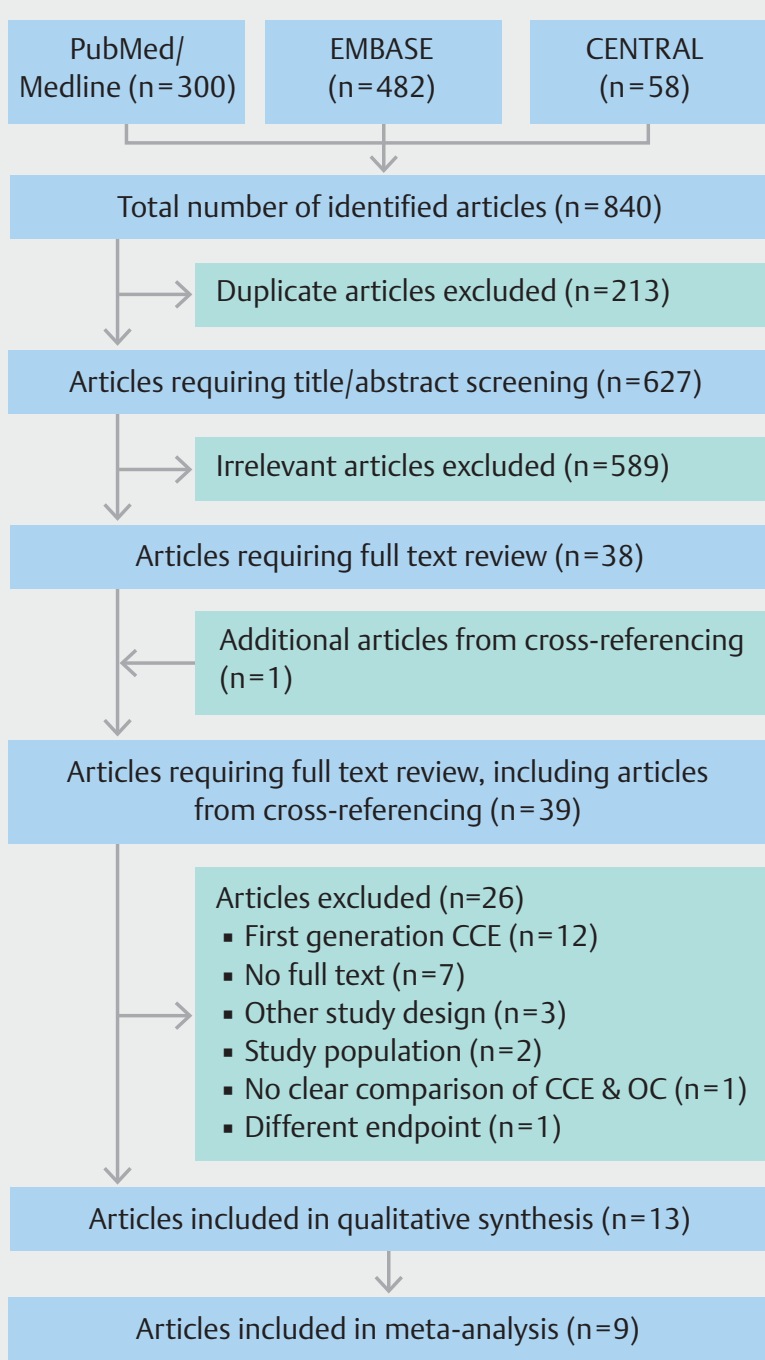

- Fig. 1 Flow diagram of the systematic literature search.

tion to either CCE-2 or OC, $33 \%(n=39)$ chose to undergo OC instead of CCE-2, while only $15 \%(n=17)$ decided to undergo CCE-2 instead of OC [25].

Regarding satisfaction, nine of 11 participants (82\%) receiving CCE-2 and OC were satisfied with the procedures in one study [25]. Another study reported similar rates of satisfaction for CCE-2 (9.1) and OC (9.4) on a 10-point scale among patients receiving both measures [26].

\section{Bowel preparation and adequate cleansing}

The findings on bowel preparation and the rate of adequate cleansing are displayed in - Table 3 . The majority (62\%) used some kind of laxative and two doses of polyethylene glycol (PEG) with 2 to $4 \mathrm{~L}$ of volume in total. In terms of boosters, seven studies (54\%) used sodium phosphate, three studies (23\%) PEG alone or in combination with other products (e.g. bisacodyl) and one study each used sodium sulfate or magnesium citrate. Ten studies $(77 \%)$ included further optional boosters in their bowel preparation protocols in case the CCE-2 did not 
- Table2 Studies considering patient perspectives and respective results.

\begin{tabular}{|c|c|c|c|c|c|}
\hline \multirow{2}{*}{$\begin{array}{l}\text { Author, } \\
\text { year }\end{array}$} & \multirow{2}{*}{$\begin{array}{l}\text { Domain(s) of } \\
\text { patient perspective }\end{array}$} & \multirow[t]{2}{*}{ Questions/questionnaire used } & \multicolumn{3}{|c|}{ Results of patient perspective } \\
\hline & & & Preference & Satisfaction & Other \\
\hline $\begin{array}{l}\text { Voska, } \\
2019[22]\end{array}$ & $\begin{array}{l}\text { Acceptability, pre- } \\
\text { ference of methods }\end{array}$ & Questionnaire (not specified) & $\begin{array}{l}105(47 \%) \text { CCE, } \\
120(53 \%) \text { OC }\end{array}$ & - & - \\
\hline $\begin{array}{l}\text { Rondonotti, } \\
2014 \text { [24] }\end{array}$ & $\begin{array}{l}\text { Preference of meth- } \\
\text { ods, reason for } \\
\text { choice }\end{array}$ & Two questions & $\begin{array}{l}39(78 \%) \text { CCE, } \\
11(22 \%) \text { CTC }\end{array}$ & - & $\begin{array}{l}\text { Reasons: bloating/mild pain } \\
\text { during CTC }\end{array}$ \\
\hline \multirow{2}{*}{$\begin{array}{l}\text { Adrian- } \\
\text { de-Ganzo, } \\
2015[25]\end{array}$} & Satisfaction & $\begin{array}{l}\text { Endoscopic Satisfaction Question- } \\
\text { naire }\end{array}$ & - & $\begin{array}{l}9(82 \%) \text { satis- } \\
\text { fied }^{1}\end{array}$ & CCE less unpleasant ${ }^{1}$ \\
\hline & Choice of CCE/OC & $\begin{array}{l}\text { Questionnaire to determine rea- } \\
\text { son for changing assigned screen- } \\
\text { ing strategy }\end{array}$ & $\begin{array}{l}\text { CCE to OC: } 39 \\
(33 \%) \text { OC to } \\
\text { CCE: } 17(15 \%)\end{array}$ & & $\begin{array}{l}\text { OC: } 35(90 \%) \text { avoid second } \\
\text { bowel preparation, } 3(8 \%) \\
\text { more confident about OC, } \\
1(3 \%) \text { unpleasant experi- } \\
\text { ence of FDR } \\
\text { CCE: } 19(100 \%) \text { fear of OC }\end{array}$ \\
\hline $\begin{array}{l}\text { Parodi, } \\
2018[26]\end{array}$ & $\begin{array}{l}\text { Satisfaction, prefer- } \\
\text { ence of methods }\end{array}$ & $\begin{array}{l}\text { Questionnaire, } 10 \text {-point scales } \\
\text { (discomfort bowel preparation, } \\
\text { swallowing of capsule, during pro- } \\
\text { cedure, nausea/pain OC, satisfac- } \\
\text { tion rate CCE/OC, preference CCE) }\end{array}$ & $\begin{array}{l}72(41 \%) \text { CCE, } \\
40(23 \%) \text { OC, } \\
65(37 \%) \text { no } \\
\text { preference }\end{array}$ & $\begin{array}{l}\text { Rate: } 9.1 \text { CCE, } \\
9.4 \text { OC }\end{array}$ & - \\
\hline
\end{tabular}

reach pre-defined sections of the gastrointestinal tract in time. The rate of adequate cleansing for CCE-2 examination ranged from $61 \%$ [29] to $92 \%[14,27]$. There was no clear indication as to which bowel preparations yielded the highest rate of adequate cleansing for CCE-2 examination.

\section{Adverse events}

The reported adverse events (AEs) for each study are shown in Table A3. In total, 240 mild AEs were reported in 2,328 participants (10.3\%). The proportion of mild AEs in study participants ranged from $1.7 \%$ [25] to $25.3 \%$ [23], of which $83 \%$ (33\% [22] to $100 \%[18,20,23,27])$ were related to the bowel preparation, $10 \%$ (8\% [19] to $75 \%$ [25]) to the OC procedure itself, and $6 \%$ (2\% [19] to $60 \%$ [26]) to the CCE procedure. A total of eight moderate or severe AEs due to the OC procedure were reported.

\section{Diagnostic accuracy of any polyps and adenomas}

The sensitivities and specificities extracted for individual studies are reported in Table A4. For any polyps, sensitivity and specificity ranged from $82 \%$ [22] to $95 \%$ [14] and $65 \%$ [14] to $86 \%$ for CCE-2 compared to OC $[18,22]$. The sensitivity and specificity of CCE-2 for adenomas $\geq 6 \mathrm{~mm}$ ranged from $81 \%$ [23] to 95 $\%$ [26] and $80 \%$ [26] to $82 \%$ compared to OC [29]. Adenomas $\geq$ $10 \mathrm{~mm}$ were detected with a sensitivity and specificity of $85 \%$ [23] to $100 \%$ [22], and $92 \%$ [26] to $98 \%$ compared to OC [22]. Adrian-de-Ganzo et al. did not report sensitivities or specificities but found no significant difference in the detection rate of non-advanced and advanced adenomas as well as significant lesions for CCE-2 and OC [25].

\section{Diagnostic accuracy for polyps $\geq 6 \mathrm{~mm}$ and $\geq 10 \mathrm{~mm}$}

The results of the meta-analyses for polyps $\geq 6 \mathrm{~mm}$ and $\geq 10 \mathrm{~mm}$ are shown in > Fig. 2, - Fig. 3, and Fig.A2. For polyps $\geq 6 \mathrm{~mm}$ ( $n=8$ studies), the pooled sensitivity, specificity, and DOR of CCE-2 were $87 \%$ (95\% Cl: $83 \%-90 \%), 87 \%$ (95\% Cl: 76\%-93\%), and 49.6 (95\%Cl: $22.1-111.4)$ with OC as the reference standard, respectively. There was significant heterogeneity present for specificity $\left(I^{2} 91 \%, P<.01\right)$ and the DOR $\left(I^{2} 71 \%, P<.01\right)$. Among the average risk screening population ( $n=2$ studies), the sensitivity and specificity of CCE-2 were $86 \%$ (95\% Cl: $80 \%-$ $90 \%$ ) and $95 \%$ (95\% Cl: $91 \%-97 \%)$ compared to OC. Among FIT/ $\mathrm{FOBT}+, \mathrm{FDR}$, and study populations with mixed indication $(\mathrm{n}=5$ studies) the sensitivity and specificity for CCE-2 were $88 \%$ (95\% Cl: $82 \%-93 \%)$ and $80 \%$ (95\% Cl: 69\%-87\%) compared to OC.

For polyps $\geq 10 \mathrm{~mm}$ ( $\mathrm{n}=9$ studies), the pooled sensitivity, specificity, and DOR of CCE-2 were $87 \%$ (95\% Cl: $83 \%-90 \%$ ), $95 \%$ (95\% Cl: $92 \%-97 \%$ ), and 140.3 (95\% Cl: 89.2-220.6) with OC as the reference standard, respectively. Significant heterogeneity was present for the specificity $\left(I^{2} 59 \%, P=.01\right)$ here as well. When stratifying the pooled estimates according to indication, the sensitivities and specificities of CCE-2 compared to OC were $85 \%$ (95\% Cl: $77 \%-91 \%$ ) and $98 \%$ (95\% Cl: $94 \%-$ $99 \%)$ for the average risk screening population ( $n=2$ studies) and $87 \%$ (95\% Cl: $82 \%-91 \%$ ) and $93 \%$ (95\% Cl: 88\%-96\%) for studies among FIT/FOBT + participants ( $n=3$ studies). For FDR or mixed populations ( $n=4$ studies), the sensitivity and specificity of CCE-2 were $89 \%$ (95\% Cl: 79\%-94\%) and 93\% (95\% Cl: $89 \%-95 \%)$ compared to OC. 
- Table 3 Bowel preparation and rate of adequate cleansing.

\begin{tabular}{|c|c|c|c|c|c|c|}
\hline \multirow[t]{3}{*}{ Author, year } & \multicolumn{5}{|l|}{ Bowel preparation } & \multirow{3}{*}{$\begin{array}{l}\text { Adequate } \\
\text { cleansing } \\
(\%) \\
\text { CCE }\end{array}$} \\
\hline & \multirow{2}{*}{$\begin{array}{l}\text { Laxative (type; } \\
\text { number; dose) }\end{array}$} & \multirow{2}{*}{$\begin{array}{l}\text { PEG } \\
\text { (doses, } \\
\text { total) }\end{array}$} & \multicolumn{3}{|l|}{ Booster } & \\
\hline & & & Type & $\begin{array}{l}\text { Volume } \\
\text { (Total) }\end{array}$ & Optional & \\
\hline Rex, 2015 [19] & Senna; $4 ; 12 \mathrm{mg}$ & $2,4 \mathrm{~L}$ & $\mathrm{NaS}$ & $6 o z$ & $\begin{array}{l}10 \mathrm{mg} \text { metoclopramide, } \\
3 \text { oz suprep, } 10 \mathrm{mg} \text { bisacodyl }\end{array}$ & 80 \\
\hline Voska, 2019 [22] & - & $2,4 \mathrm{~L}$ & $\mathrm{NaP}$ & $30 \mathrm{~mL}$ & $\begin{array}{l}25 \mathrm{~mL} \mathrm{NaP}, 2 \text { g glycerin } \\
\text { suppository }\end{array}$ & 90 \\
\hline Holleran, 2014 [14] & Senna; 4; NA & $2,4 \mathrm{~L}$ & $\mathrm{NaP}$ & $75 \mathrm{~mL}$ & $10 \mathrm{mg}$ bisacodyl & 92 \\
\hline Rondonotti, 2014 [24] & Bisacodyl; 4; $5 \mathrm{mg}$ & $2,200 \mathrm{~g}$ & $\mathrm{NaP}$ & $45 \mathrm{~mL}$ & - & 70 \\
\hline $\begin{array}{l}\text { Kobaek-Larsen, } 2017 \\
{[21]}\end{array}$ & $\begin{array}{l}\text { Magnesium } \\
\text { oxide; } 2 ; 1000 \mathrm{mg}\end{array}$ & $2,2 \mathrm{~L}$ & $\begin{array}{l}\text { PEG } \\
\text { Bisacodyl }\end{array}$ & $\begin{array}{l}1 \mathrm{~L} \\
10 \mathrm{mg}\end{array}$ & - & 85 \\
\hline Pecere, 2019 [23] & Senna; 4 & $2,4 \mathrm{~L}$ & $\mathrm{NaP}$ & $60 \mathrm{~mL}$ & $10 \mathrm{mg}$ bisacodyl & 88 \\
\hline $\begin{array}{l}\text { Adrian-de-Ganzo, } \\
2015 \text { [25] }\end{array}$ & Senna; NA; 24 mg & $2,2.3 \mathrm{~L}$ & PEG & $50 \mathrm{mg}$ & $\begin{array}{l}50 \mathrm{mg} \text { PEG, } 15 \mathrm{mg} \text { mosa- } \\
\text { pride, } 10 \mathrm{mg} \text { bisacodyl }\end{array}$ & 80 \\
\hline Parodi, 2018 [26] & - & $2,4 \mathrm{~L}$ & $\mathrm{NaP}$ & $40 \mathrm{~mL}$ & $\begin{array}{l}10 \mathrm{mg} \text { metoclopramide, } \\
20 \mathrm{~mL} \mathrm{NaP}, 10 \mathrm{mg} \text { bisacodyl }\end{array}$ & 68 \\
\hline Kroijer, 2019 [27] & - & $2,2 \mathrm{~L}$ & $\begin{array}{l}\text { PEG } \\
\text { Sulfate-based } \\
\text { PEG + gastrografin }\end{array}$ & $\begin{array}{l}1 \mathrm{~L} \\
1 \mathrm{~L} \\
1 \mathrm{~L}+75 \mathrm{~mL}\end{array}$ & $10 \mathrm{mg}$ bisacodyl & 92 \\
\hline Eliakim, 2009 [20] & - & $2,2 \mathrm{~L}$ & $\mathrm{NaP}$ & $30 \mathrm{~mL}$ & $15 \mathrm{~mL} \mathrm{NaP}, 10 \mathrm{mg}$ bisacodyl & 78 \\
\hline Spada, $2011[28]$ & Senna; $4 ; 12 \mathrm{mg}$ & $2,2 \mathrm{~L}$ & $\mathrm{NaP}$ & $55 \mathrm{~mL}$ & $10 \mathrm{mg}$ bisacodyl & 81 \\
\hline Hagel, 2014 [18] & Senna; 4; NA & $2,2 \mathrm{~L}$ & $\mathrm{NaP}$ & $30 \mathrm{~mL}$ & $15 \mathrm{~mL} \mathrm{NaP}, 10 \mathrm{mg}$ bisacodyl & 90 \\
\hline Morgan, 2016 [29] & - & $2,4 \mathrm{~L}$ & Magnesium citrate & $8 \mathrm{oz}$ & $\begin{array}{l}10 \mathrm{mg} \text { metoclopramide } \\
5 \mathrm{oz} \text { magnesium citrate } \\
10 \mathrm{mg} \text { bisacodyl }\end{array}$ & 61 \\
\hline
\end{tabular}

CCE, colon capsule endoscopy; NA, not available; NaP, sodium phosphate; NaS, sodium sulfate; PEG, polyethylene glycol.

\section{Discussion}

This systematic review and meta-analysis focused on the diagnostic accuracy, patient perspective, bowel preparation and rate of adequate cleansing in clinical trials comparing CCE-2 and OC. Our review is an update of a previously performed analysis [12], including recently published data, and with additional focus on patient perspective regarding CCE. We found that CCE-2 has a high diagnostic accuracy for polyps $\geq 6 \mathrm{~mm}$ and $\geq 10 \mathrm{~mm}$. Most adverse events were mild and usually related to bowel preparation rather than the CCE examination itself and the rate of adequate bowel cleansing varied widely among studies. Furthermore, there is mixed evidence on whether or not CCE-2 might be accepted by average risk screening individuals.

The results of our systematic review and meta-analysis are important when considering CCE-2 as a regular CRC screening examination. First, the overall diagnostic accuracy of CCE- 2 for polyps and adenomas was adequate and supports the implementation of CCE-2 as a valuable screening option. This is in line with the previously published meta-analysis by Spada et al. [12], but is corroborated by additional clinical trials $(n=4)$. When considering the accuracy of CCE-2 compared to OC for any polyps (regardless of size), the sensitivity was similar to those for polyps $\geq 6 \mathrm{~mm}$ and highest among FIT + participants (95\%) [14]. Yet, the specificities for polyps of any size were considerably lower than the specificities for larger polyps ( $\geq 6 \mathrm{~mm}$ ). Only in a few studies, histopathologic diagnoses were reported. Here, adenomas $\geq 6 \mathrm{~mm}$ and $\geq 10 \mathrm{~mm}$ showed similar sensitivities as "polyps" of the same size (up to $95 \%$ among FDR of CRC patients [26]). Specificities were only comparable for adenomas and "polyps" $\geq 10 \mathrm{~mm}$. Regarding the meta-analyses of polyps $\geq 6 \mathrm{~mm}$ and $\geq 10 \mathrm{~mm}$, the high overall diagnostic accuracy is a good argument to include CCE- 2 in routine CRC screening. However, only two studies were conducted in cohorts of individuals with average CRC risk $[19,22]$, which underlines the need for further studies in the screening population. The results from the pooled analysis of FIT/FOBT + participants indicate that CCE-2 might indeed be a valuable method to offer as an alternative to OC for FIT/FOBT positive individuals [14,21, 


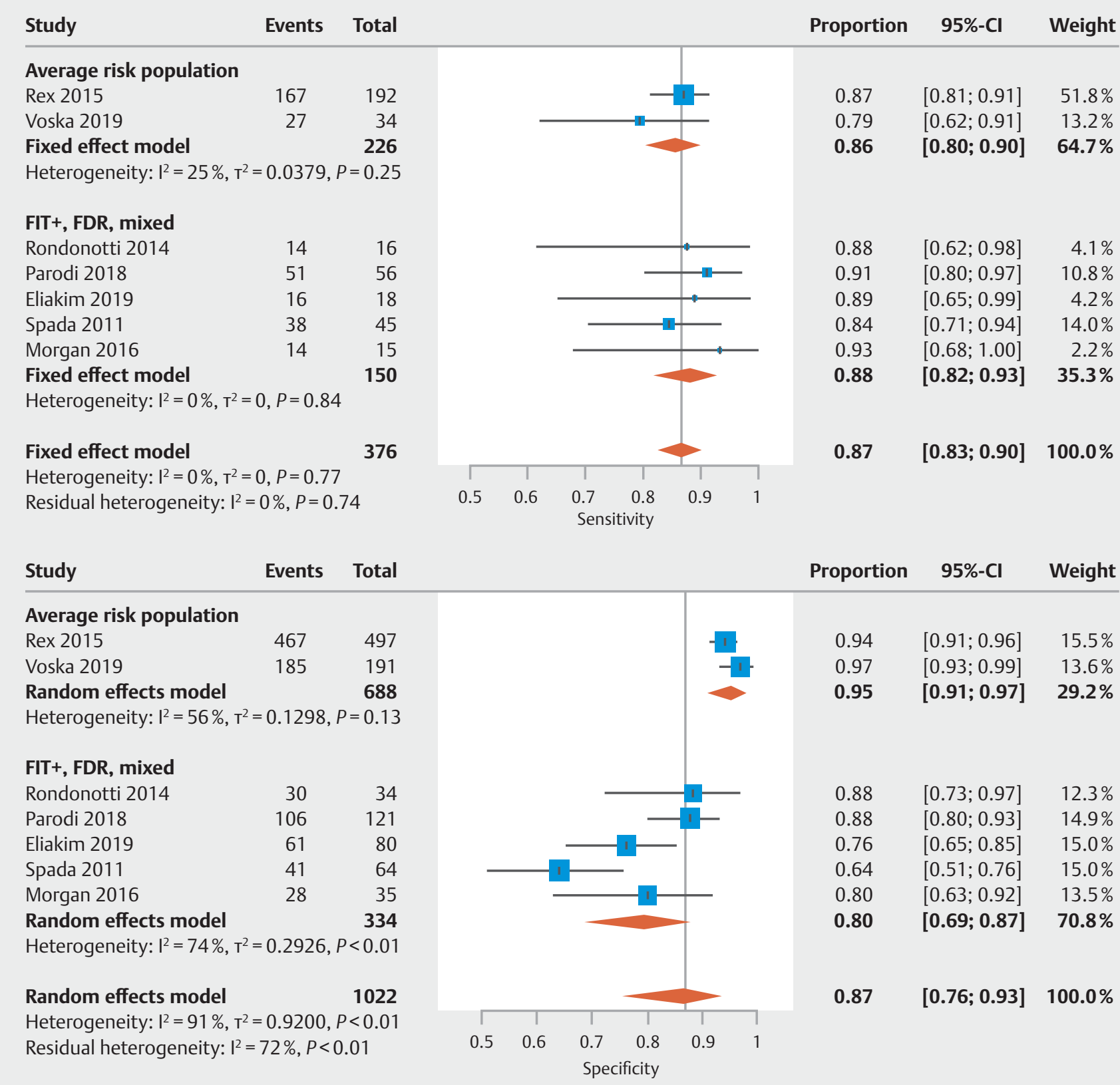

Fig. 2 Forest plots showing the pooled sensitivity and specificity of CCE-2 for polyps $\geq 6 \mathrm{~mm}$.

24]. It is important to note that due to the miss-rate of polyps in OC [30] and OC being the reference standard, the number of false-positive results of CCE might be overestimated. Hence, the diagnostic accuracy of CCE-2 might be even higher than reported and advances in technology including a third generation of CCE might enhance the diagnostic accuracy even more. In sum, CCE-2 is a valuable option for CRC screening. Other than a standard screening option, it could also be offered to patients at a higher risk for CRC (FIT/FOBT + or FDR) as a selector for referral to colonoscopy with polyp removal.

Only four of 13 clinical trials comparing CCE-2 to OC (31\%) reported the patient perspective. Patients' acceptance of screening methods is crucial as perception of risk and benefit determines the success of a screening measure. The available studies do not indicate preference for OC [22] vs. CCE-2 [26]. Additionally, in a trial among FDR of CRC patients, where participants could still choose between OC or CCE after being randomly assigned to one group, more participants chose OC over CCE-2 than vice versa. Interestingly, the screening adherence was similar in both groups (CCE-2: 57\%, OC: 56\%) [25]. However, awareness of CRC is probably higher among FDR, and the higher probability of polyp detection might have led to the decision for $\mathrm{OC}$, which allows detection and removal within one single procedure. According to one study, the lay public prefers non-invasive procedures (CTC or CCE) to OC for general diagnostic purposes but not after a positive FIT/FOBT 


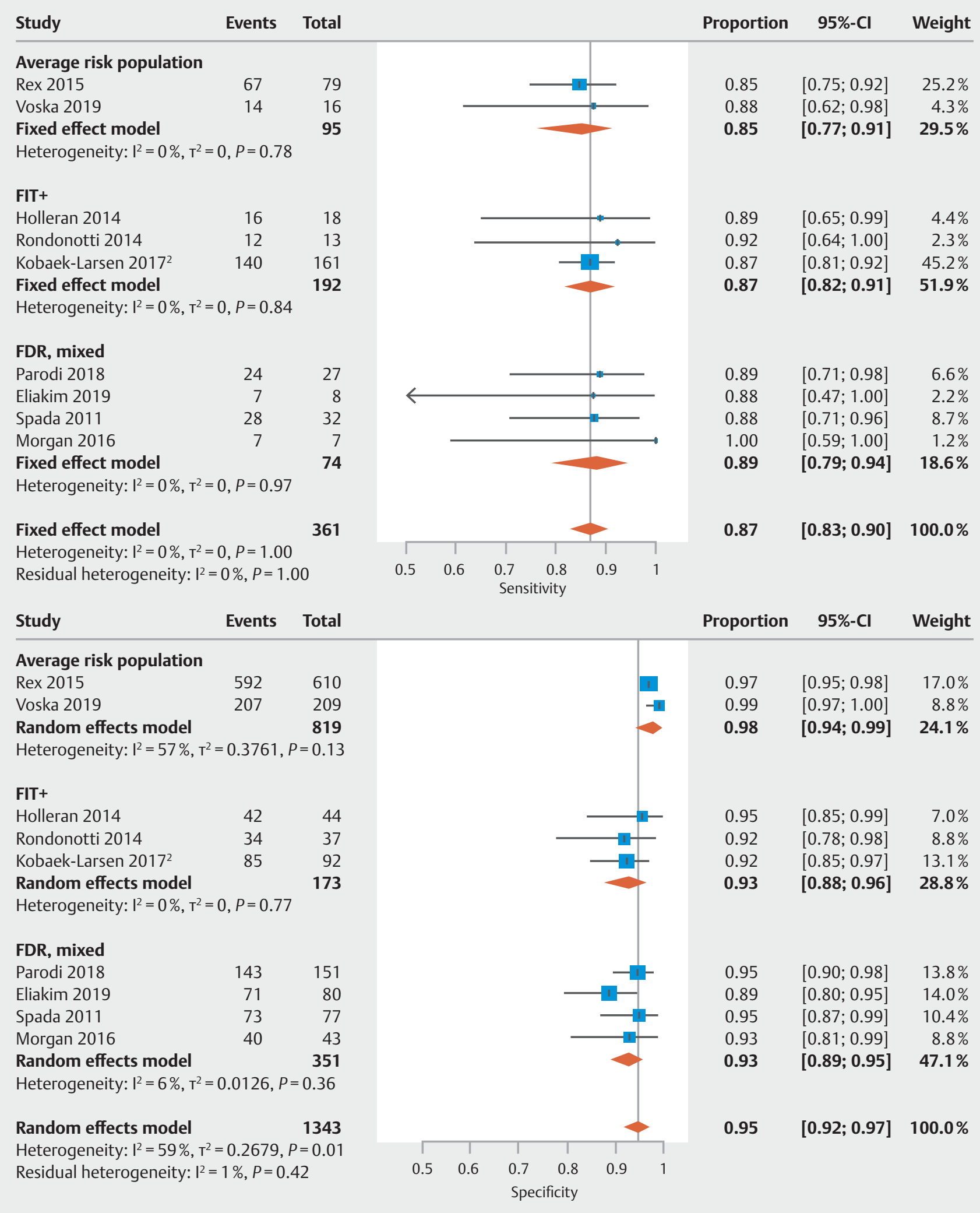

- Fig. 3 Forest plots showing the pooled sensitivity and specificity of CCE-2 for polyps $\geq 10 \mathrm{~mm}$. 
test [31]. In another study on FIT + individuals, CCE-2 was preferred over CTC [24]. To our knowledge, there was a single study investigating average risk screening population, coming with a 4-fold increase of screening uptake, when offering CCE as an alternative to OC [13]. Thus, offering CCE as an alternative outpatient procedure might result in increasing screening adherence [32]. Currently, the cost for a CCE-2 procedure is priced at about 1,000 EUR [33], which might decrease when implemented as a screening option including automated imaging analysis. Nevertheless, to be considered cost-effective, an increase of screening uptake of $20 \%$ or more for CCE-2 over OC is required [33]. Also, at defecation, the capsule mostly gets disposed in the toilet, which is not a sustainable solution for a high-tech product. A better concept will be needed for capsule recovery when the capsule is offered to a large number of people. In summary, future research should focus on the perspective of the screening individual, including the question whether offering CCE would increases participation among average risk individuals.

Overall, the various bowel preparation protocols resulted in a wide range of bowel cleanliness at CCE-2 examination (61\%$92 \%$ "adequate cleansing"). There did not seem to be a clear indication as to which bowel preparation regimen yields the highest cleansing rate. For example, among the four studies with a cleansing rate of $\geq 90 \%$, two used laxatives $[14,18]$ and two did not $[22,27]$. Furthermore, they included different volumes of PEG and types and volumes of boosters and optional boosters. Notwithstanding these uncertainties, the rate of adequate cleansing remains a central issue for the success of CCE examinations, as this influences the diagnostic accuracy [34]. On the other hand, by pushing for more extensive or complicated bowel preparations to reach adequate levels of cleansing, the possibility of discouraging patients and physician alike from considering CCE at all is quite real. It is clear that a proportion of patients will not choose CCE in the first place to avoid the second bowel preparation in case of positive findings [25].

\section{Strengths and weaknesses}

Our systematic review and meta-analysis has several strengths. It gives an update on the diagnostic accuracy of CCE-2 for polyps $\geq 6 \mathrm{~mm}$ and $\geq 10 \mathrm{~mm}$, which includes three $(\geq 6 \mathrm{~mm}$ ) and four $\geq 10 \mathrm{~mm}$ ) new studies. Additionally, we conducted stratified analyses based on the indication for CCE-2 and OC examination. Furthermore, we were able to include multiple studies that also analyzed adenomas confirmed by histopathology. An additional aim of the review was the assessment of the patient perspective, which revealed that clinical trials on CCE-2 and $\mathrm{OC}$ have rarely reported the patient perspective in depth.

A general limitation is the small number of studies that could be included in the meta-analysis based on our protocol. In addition, the number of newly published clinical trials is very low $(n=4)$ since the last meta-analysis was published in 2016. The reasons might range from a poor adaptation of the technology to awaiting the third generation of CCE, the focus on the patient perspective of CCE-2 or the evaluation of the impact of CCE-2 on screening participation. There is a scarcity of studies among different populations (average risk, FIT/FOBT + or FDR) that prohibits generalization of our results. Another main limitation of this meta-analysis is the heterogeneity of specificities, which was partially controlled by our approach using random-effects models. Furthermore, the low number of studies reporting the patient perspective and the heterogenous assessment do not allow for a clear conclusion on the patient perspective. For more extensive data on the patient perspective and bowel preparation, separate reviews focusing on those outcomes might be needed.

\section{Conclusion}

In conclusion, CCE-2 yields appropriate diagnostic accuracy for polyps $\geq 6 \mathrm{~mm}$ and $\geq 10 \mathrm{~mm}$ in an adequately cleaned large bowel to be implemented in CRC screening. Future studies are needed to elucidate clinical utility with a specific focus on patient perspectives on CCE-2.

\section{Acknowledgments}

This work was supported by the German Federal Ministry of Education and Research (01KD1907A, 01KD1907B), and the Robert Bosch Stiftung, Stuttgart, Germany.

\section{Competing interests}

The authors declare that they have no conflict of interest.

References

[1] Fitzmaurice C, Abate D. Global Burden of Disease Cancer Committee. et al. Global, regional, and national cancer incidence, mortality, years of life lost, years lived with disability, and disability-adjusted life-years for 29 cancer groups, 1990 to 2017: a systematic analysis for the global burden of disease study. JAMA Oncol 2019; 12: 1749-1769

[2] Brenner $\mathrm{H}$, Altenhofen L, Stock $\mathrm{C}$ et al. Natural history of colorectal adenomas: birth cohort analysis among 3.6 million participants of screening colonoscopy. Cancer Epidemiol Biomarkers Prev 2013; 22: 1043-1051

[3] Brenner $\mathrm{H}$, Chen $\mathrm{C}$. The colorectal cancer epidemic: challenges and opportunities for primary, secondary and tertiary prevention. $\mathrm{Br}$ J Cancer 2018; 119: 785-792

[4] Brenner H, Altenhofen L, Stock C et al. Prevention, early detection, and overdiagnosis of colorectal cancer within 10 years of screening colonoscopy in Germany. Clin Gastroenterol Hepatol 2015; 13: 717723

[5] Hoffmeister M, Holleczek B, Zwink $N$ et al. Screening for bowel cancer: increasing participation via personal invitation. Dtsch Arztebl Int 2017; 114: 87-93

[6] Stratmann K, Bock H, Filmann $\mathrm{N}$ et al. Individual invitation letters lead to significant increase in attendance for screening colonoscopies: Results of a pilot study in Northern Hesse, Germany. United European Gastroenterol J 2018; 6: 1082-1088

[7] van der Vlugt M, Grobbee EJ, Bossuyt PM et al. Adherence to colorectal cancer screening: four rounds of faecal immunochemical testbased screening. Br J Cancer 2017; 116: 44-49

[8] Chen C, Stock C, Hoffmeister M et al. Public health impact of colonoscopy use on colorectal cancer mortality in Germany and the United States. Gastrointest Endosc 2018; 87: 213-221 
[9] Honein-AbouHaidar GN, Kastner M, Vuong V et al. Systematic review and meta-study synthesis of qualitative studies evaluating facilitators and barriers to participation in colorectal cancer screening. Cancer Epidemiol Biomarkers Prev 2016; 25: 907-917

[10] Spada C, Hassan C, Galmiche JP et al. Colon capsule endoscopy: European Society of Gastrointestinal Endoscopy (ESGE) Guideline. Endoscopy 2012; 44: 527-536

[11] Baltes P, Bota M, Albert J et al. PillCamColon2 after incomplete colonoscopy - A prospective multicenter study. World J Gastroenterol 2018; 24: 3556-3566

[12] Spada C, Pasha SF, Gross SA et al. Accuracy of first- and second-generation colon capsules in endoscopic detection of colorectal polyps: a systematic review and meta-analysis. Clin Gastroenterol Hepatol 2016; 14: 1533-1543.e8

[13] Groth S, Krause H, Behrendt R et al. Capsule colonoscopy increases uptake of colorectal cancer screening. BMC Gastroenterol 2012: doi:10.1186/1471-230X-12-80

[14] Holleran G, Leen R, O'Morain C et al. Colon capsule endoscopy as possible filter test for colonoscopy selection in a screening population with positive fecal immunology. Endoscopy 2014; 46: 473-478

[15] Whiting PF, Rutjes AW, Westwood ME et al. QUADAS-2: a revised tool for the quality assessment of diagnostic accuracy studies. Ann Intern Med 2011; 155: 529-536

[16] Schwarzer G. General package for meta-analysis. 2020: Available from (Accessed 2020 April 22): https://cran.r-project.org/web/ packages/meta/meta.pdf

[17] Doebler P, Holling $\mathrm{H}$. Meta-analysis of diagnostic accuracy with mada. 2017: Available from (Accessed 2020 April 22): https://cran.r-project.org/web/packages/mada/vignettes/mada.pdf

[18] Hagel AF, Gabele E, Raithel M et al. Colon capsule endoscopy: detection of colonic polyps compared with conventional colonoscopy and visualization of extracolonic pathologies. Can J Gastroenterol Hepatol 2014; 28: 77-82

[19] Rex DK, Adler SN, Aisenberg J et al. Accuracy of capsule colonoscopy in detecting colorectal polyps in a screening population. Gastroenterology 2015; 148: 948-957.e2

[20] Eliakim R, Yassin K, Niv Y et al. Prospective multicenter performance evaluation of the second-generation colon capsule compared with colonoscopy. Endoscopy 2009; 41: 1026-1031

[21] Kobaek-Larsen M, Kroijer R, Dyrvig AK et al. Back-to-back colon capsule endoscopy and optical colonoscopy in colorectal cancer screening individuals. Colorectal Dis 2018; 20: 479-485
[22] Voska M, Zavoral M, Grega T et al. Accuracy of colon capsule endoscopy for colorectal neoplasia detection in individuals referred for a screening colonoscopy. Gastroenterol Res Pract 2019: doi:10.1155/ 2019/5975438

[23] Pecere S, Senore C, Hassan C et al. Accuracy of colon capsule endoscopy for advanced neoplasia. Gastrointest Endosc 2019: doi:10.1016/ j.gie.2019.09.041

[24] Rondonotti E, Borghi C, Mandelli G et al. Accuracy of capsule colonoscopy and computed tomographic colonography in individuals with positive results from the fecal occult blood test. Clin Gastroenterol Hepatol 2014; 12: 1303-1310

[25] Adrian-de-Ganzo Z, Alarcon-Fernandez O, Ramos L et al. Uptake of colon capsule endoscopy vs colonoscopy for screening relatives of patients with colorectal cancer. Clin Gastroenterol Hepatol 2015; 13 : 2293-2301.e1

[26] Parodi A, Vanbiervliet G, Hassan C et al. Colon capsule endoscopy to screen for colorectal neoplasia in those with family histories of colorectal cancer. Gastrointest Endosc 2018; 87: 695-704

[27] Kroijer R, Kobaek-Larsen M, Qvist N et al. Colon capsule endoscopy for colonic surveillance. Colorectal Dis 2019; 21: 532-537

[28] Spada C, Hassan C, Munoz-Navas M et al. Second-generation colon capsule endoscopy compared with colonoscopy. Gastrointest Endosc 2011; 74: 581-589.e1

[29] Morgan DR, Malik PR, Romeo DP et al. Initial US evaluation of secondgeneration capsule colonoscopy for detecting colon polyps. BM] Open Gastroenterol 2016: doi:10.1136/bmjgast-2016-000089

[30] Heresbach D, Barrioz T, Lapalus MG et al. Miss rate for colorectal neoplastic polyps: a prospective multicenter study of back-to-back video colonoscopies. Endoscopy 2008; 40: 284-290

[31] Ojidu H, Palmer H, Lewandowski J et al. Patient tolerance and acceptance of different colonic imaging modalities: an observational cohort study. Eur J Gastroenterol Hepatol 2018; 30: 520-525

[32] Adler SN, Hassan C, Metzger Y et al. Second-generation colon capsule endoscopy is feasible in the out-of-clinic setting. Surg Endosc 2014 28: $570-575$

[33] Hassan C, Zullo A, Winn S et al. Cost-effectiveness of capsule endoscopy in screening for colorectal cancer. Endoscopy 2008; 40: 414421

[34] Van Gossum A, Navas MM, Fernandez-Urien I et al. Capsule endoscopy versus colonoscopy for the detection of polyps and cancer. $\mathrm{N}$ Engl J Med 2009; 361: 264-270 